\title{
Potencial adaptativo de populações de Rhizoctonia solani AG-1 IA associadas ao arroz e à Urochloa brizantha ao estresse térmico
}

\author{
Lina Maria Ramos-Molina ${ }^{1} \oplus$, Paulo Cezar Ceresini ${ }^{1} \oplus$, Samara Nunes Campos Vicentini ${ }^{1} \oplus$, Danilo Augusto dos \\ Santos Pereira ${ }^{1} \oplus$, Grace Ingrid Conceição ${ }^{1}$, María del Rosario Silva-Herrera ${ }^{2}$, Pedro César dos Santos ${ }^{1}$
}

\begin{abstract}
${ }^{1}$ Universidade Estadual Paulista - UNESP, Campus de Ilha Solteira, CEP 15385-000, Ilha Solteira, SP, Brasil. ${ }^{2}$ Universidad de Los Llanos, Villavicencio, Meta, Colômbia.

Autor para correspondência: Paulo Cezar Ceresini (paulo.ceresini@unesp.br).

Data de chegada: 10/09/2017. Aceito para publicação em: 04/02/2019.
\end{abstract}

$10.1590 / 0100-5405 / 185143$

\section{RESUMO}

Ramos-Molina, L.M.; Ceresini, P.C.; Vicentini, S.N.C.; Pereira, D.A.S.; Conceição, G.I.; Silva-Herrera, M.R.; Santos, P.C.. Potencial adaptativo de populações de Rhizoctonia solani AG-1 IA associadas ao arroz e à Urochloa brizantha ao estresse térmico. Summa Phytopathologica, v.45, n.3, p.320-325, 2019.

Muitos fitopatógenos de ampla distribuição geográfica como os fungos fitopatogênicos do gênero Rhizoctonia, estão sujeitos a extremas flutuações de temperatura em seus habitats. Para sobreviver a tais flutuações térmicas, esses organismos desenvolveram a habilidade de regular seus valores fenotípicos para adaptações térmicas bem como a outras variações ambientais específicas. O objetivo do presente estudo foi determinar o efeito do estresse térmico na evolucionabilidade para crescimento micelial de duas populações hospedeiro-distintas de Rhizocctonia solani AG-1 IA infectando arroz (OS6) ou Urochloa (BBT1) e compará-las a uma população de R. oryzae-sativae de arroz (OS5), espécie adaptada a temperaturas mais elevadas. As populações foram submetidas a duas temperaturas de crescimento: $25^{\circ} \mathrm{C}$ e $35^{\circ} \mathrm{C}$ (temperatura ótima e de estresse para $R$. solani AG-1 IA). Baseando-se em medidas do crescimento micelial, estimaramse os coeficientes de variância genotípica $\left(I_{G}\right)$, variância ambiental $\left(I_{E}\right)$ e herdabilidade no sentido amplo $\left(h^{2}\right)$ como medidas de evolucionabilidade. Enquanto a população OS5 de $R$. oryzae-sativae foi pouco influenciada pelo estresse térmico, a $35^{\circ} \mathrm{C}$ detectou-se redução de $h^{2}$ nas populações BBT1 e OS6 de $R$. solani AG-1 IA. Entretanto, os valores relativamente altos de $h^{2}$ a $35^{\circ} \mathrm{C}(0,63 \pm 0,07)$ indicaram que tanto a população BBT1 quanto a OS6 de $R$. solani AG-1 IA têm potencial de adaptação ao estresse térmico.

Palavras-chave: Variância genética; adaptação térmica; estresse ambiental; evolucionabilidade.

\begin{abstract}
Ramos-Molina, L.M.; Ceresini, P.C.; Vicentini, S.N.C.; Pereira, D.A.S.; Conceição, G.I.; Silva-Herrera, M.R.; Santos, P.C. Adaptive potential of Rhizoctonia solani AG-1 IA populations associated with rice and Urochloa brizantha for thermal stress. Summa Phytopathologica, v.45, n.3, p.320-325, 2019.

A large number of widely distributed plant pathogens such as the phytopathogenic fungi of the genus Rhizoctonia are subject to extreme temperature fluctuations in their habitats. To survive such thermal fluctuations, these organisms have developed the capability of regulating their phenotypic values for specific thermal adaptations and to other specific environmental variations. The objective of this study was to determine the effects of thermal stress on the evolvability for mycelial growth in two host-distinct populations of Rhizoctonia solani AG-1 IA infecting either rice (OS6) or Urochloa (BBT1), and to compare them with a population of $R$. oryzae-sativae from rice (OS5), a species adapted to higher temperatures.

The populations were subjected to two growth temperatures: $25^{\circ} \mathrm{C}$ and $35^{\circ} \mathrm{C}$ (optimal and stress temperatures for $R$. solani AG-1 IA). Based on mycelial growth, estimates of genotypic variance $\left(I_{G}\right)$, environmental variance $\left(I_{E}\right)$ and broad sense heritability $\left(h^{2}\right)$ were determined as measures of evolvability. The population OS5 of $R$. oryzae-sativae was almost not influenced by temperature stress, while at $35^{\circ} \mathrm{C}$ there was a reduction in $h^{2}$ for the populations BBT1 and OS6 of $R$. solani AG-1 IA. However, the relatively high $h^{2}$ values for mycelial growth at $35^{\circ} \mathrm{C}(0.63 \pm 0.07)$ indicate that both populations BBT1 and OS6 of $R$. solani AG-1 IA have potential for adaptation to temperature stress.
\end{abstract}

Keywords: Genetic variance; thermal adaptation; environmental stress; evolvability.

Na América do Sul o fungo basidiomiceto Thanatephorus cucumeris (Rhizoctonia solani em sua fase assexual) emergiu na década de 1990 como um importante patógeno da queima das folhas e morte de pastagens do gênero Urochloa (9). R. solani compreende várias unidades taxonômicas correspondentes a espécies filogenéticas e/ou biológicas, denominadas de grupos de anastomose (AGs) (13). Em levantamento efetuado nos Llanos orientais colombianos, $R$. solani AG-1 IA predominou como patógeno da queima da folha e morte de Urochloa $(2,25)$. Em extensa amostragem na Amazônia brasileira, foi também observada predominância de $R$. solani AG-1 IA em pastagens de Urochloa do estado de Rondônia (8).

O fungo $R$. solani AG-1 IA apresenta ampla distribuição geográfica como patógeno necrotrófico habitante do solo, e infecta Poáceas e Fabáceas em regiões de clima tropical e subtropical, causando principalmente a queima da bainha no arroz $(7,17)$. Além de patógeno de Urochloa, há relatos da associação de $R$. solani AG-1 IA à mela da soja $(7,17)$ e à mancha bandeada do milho $(6)$. Observações sobre a biologia de populações de $R$. solani AG-1 IA feitas na última década sugerem que este patógeno possui alto potencial evolutivo $(8,14,23)$. Há evidências para a emergência de populações especializadas de 
R. solani AG-1 IA via troca [do arroz para o milho (14)] ou salto de hospedeiros [do arroz para a soja (5)]. Quanto à origem das populações de $R$. solani AG-1 IA que infectam Urochloa na América do Sul, é indicado que tenham emergido de populações que originalmente infectavam o arroz (8).

Muitos fitopatógenos que apresentam ampla distribuição geográfica, como $R$. solani AG-1 IA, estão sujeitos a extremas flutuações de temperatura em seus habitats, especialmente devido às diferenças climáticas entre esses ambientes. Logo, para sobreviver a flutuações climáticas, esses organismos desenvolveram a habilidade de constantemente regular seus valores fenotípicos para adaptações térmicas específicas (30). Para espécies do complexo Rhizoctonia spp. o crescimento micelial é um importante componente adaptativo, uma vez que os danos às plantas resultam principalmente da infecção por hifas assexuais (19). Além disso, o rápido crescimento micelial de Rhizoctonia spp. lhe confere alta habilidade de competição saprofítica (21).

Condições de estresse térmico em temperaturas acima do ótimo, por sua vez, resultam em supressão do crescimento micelial fúngico em função de alterações nas características morfológicas e fisiológicas das hifas, por exemplo septura e crescimento anormais, redução da quantidade de quitina na parede celular, desnaturação de proteínas, desintegração de mitocôndrias e autólise extensa. Relata-se, inclusive, diminuição no teor total de proteínas intracelulares e um aumento acentuado em proteínas danificadas oxidativamente (1).

Análises experimentais do crescimento micelial sob condições de estresse de temperatura, associadas às medidas de variância genética aditiva e de evolucionabilidade deste carácter, nos permitiriam inferir sobre o potencial adaptativo de $R$. solani AG-1 IA à variações térmicas ambientais, de forma semelhante ao procedimento usado para determinar a adaptabilidade evolutiva do patógeno a novos hospedeiros $(22,23,27)$. Isso porque evolucionabilidade é definida como a capacidade para a evolução adaptativa ou do potencial adaptativo de uma população, i.e., medidas de resposta à seleção $(15,28,29)$ que, no caso de fitopatógenos, pode ser imposta por estresses ambientais (28, $30)$ ou por variantes biológicas dos hospedeiros $(22,23,27)$.

Assim sendo, este estudo teve dois objetivos: (i) determinar se populações de $R$. solani AG-1 IA associadas à Urochloa e ao arroz, respondem de forma semelhante ao estresse de temperatura elevada; (ii) testar o efeito do aumento de temperatura sobre a variância genética e a herdabilidade para crescimento micelial de duas populações de $R$. solani AG-1 IA obtidas de Urochloa ou do arroz. Uma terceira população de outra espécie de Rhizoctonia associada ao arroz (R. oryzae-sativae, classificada como Ceratobasidium oryzae-sativae em sua fase sexuada) foi incluída neste estudo para efeito comparativo. O fungo R. oryzaesativae (agente causal da mancha agregada da bainha do arroz) é adaptado a temperaturas mais elevadas, com ótimo de crescimento a $32^{\circ} \mathrm{C}$ (3) e ocorre naturalmente em áreas de arroz na Colômbia (22, 25). Nossa hipótese foi de que o estresse imposto pelo aumento da temperatura afetaria, de forma semelhante, o potencial adaptativo de R. solani AG-1 IA, obtido de Urochloa e de arroz.

\section{MATERIAL E MÉTODOS}

Em 2010, campos de arroz e Urochloa foram amostrados em três áreas de produção no Estado de Meta, nos Llanos orientais colombianos (Figura 1). Plantas com sintomas de queima da folha de Urochloa, queima da bainha ou de mancha agregada do arroz, foram coletadas de dois a três focos de infestação (com pelo menos $10 \mathrm{~m}$ de distância entre eles) em cada linha, com um total de 4 a 6 linhas por campo. No município de Puerto Lopez foram obtidas amostras de dois hospedeiros: Urochloa brizantha cv. Toledo (BBT1) e arroz (OS6). Já no município de Villavicencio, um terceiro conjunto de amostras foi coletado de arroz (OS5).

Para realizar os isolamentos dos patógenos, fragmentos de material vegetal infectado foram desinfestados com hipoclorito de sódio a 1\%, e posteriormente transferidos para meio batata-dextrose-ágar (BDA). Os isolamentos foram incubados a $25^{\circ} \mathrm{C}$ no escuro, durante três dias, e em seguida purificados em meio BDA. Ao todo 36 isolados de Rhizoctonia spp foram obtidos, doze de cada população.

A identificação dos isolados amostrados foi baseada na detecção via reação de polimerase em cadeia (PCR) com marcadores específicos para $R$. solani AG1-IA (20) e para $R$. oryzae-sativae (16), conforme descrito anteriormente $(8,22)$. Vinte e quatro isolados obtidos das populações BBT1 de Urochloa e OS6 de arroz foram identificados como $R$. solani AG-1 IA e os outros 12 obtidos da população OS5 de arroz foram identificados como $R$. oryzae-sativae. Todos os isolados apresentaram distintos genótipos multilocos microssatélites $(8,22)$.

Para determinar o efeito do estresse térmico sobre o crescimento micelial de Rhizoctonia spp., o delineamento experimental utilizado foi o inteiramente casualizado em esquema fatorial ( $3 \times 2)$, com cinco repetições, cujos fatores foram representados por três populações dos patógenos ( $R$. solani AG1-IA BBT1 de Urochloa e OS6 do arroz e $R$. oryzae-sativae OS5 do arroz) e duas temperaturas de crescimento $\left(25\right.$ e $\left.35^{\circ} \mathrm{C}\right)$.

Cada população foi composta por doze isolados do patógeno. Para preparo de inóculo dos fungos, discos de micélio com $6 \mathrm{~mm}$ de diâmetro foram transferidos para placas de Petri contendo $20 \mathrm{~mL}$ de meio BDA (suplementado com $50 \mu \mathrm{g} / \mathrm{mL}$ de cloranfenicol e estreptomicina). As culturas foram incubadas a temperatura de $25^{\circ}$ no escuro, considerada ótima, e a $35^{\circ} \mathrm{C}$, considerada de estresse para $R$. solani AG-1 IA (10). A avaliação do crescimento micelial foi feita medindo-se o diâmetro das colônias, após 24 h de incubação. O experimento foi repetido uma vez.

Os dados de crescimento micelial $(x)$ foram transformados em logaritmo $(x+1)$. Primeiramente, foram analisados os efeitos de populações como fator fixo, de isolados dentro de cada população, do ambiente e da interação isolado x ambiente. $\mathrm{O}$ efeito de isolados foi considerado como efeito aleatório e o do ambiente como efeito fixo. A análise de variância foi realizada usando o procedimento estatístico PROC MIXED implementado no programa SAS (26). As médias do crescimento micelial do fungo dentro de cada população e em diferentes ambientes foram comparadas pelo teste de $t$ de SNK (Student-NewmanKeuls), implementado no SAS.

Para análise do efeito do ambiente sobre os componentes de evolucionabilidade (15), a variância apresentada pelos isolados dentro de cada população foi interpretada como variância genética $\left(V_{G}\right)$, o erro experimental foi considerado como variância ambiental $\left(V_{E}\right)$, e a variância fenotípica $\left(V_{P}\right)$ como o resultado da soma das variâncias genética e ambiental (28). Os componentes de variância foram determinados por procedimento estatístico implementado no programa $R(24)$.

As variâncias obtidas foram padronizadas pelo quadrado da média do crescimento micelial dos genótipos (ou isolados) do patógeno dentro de cada população $\left(m_{i}^{2}, i=1 . . . n\right.$ genótipos), onde: $V_{G} / m_{i}^{2}=I_{G i} ; V_{E} / m_{i}^{2}=I_{E i} ;$ e $V_{P} / m_{i}^{2}=I_{P}$, sendo então consideradas medidas de evolucionabilidade ou de resposta à seleção (15).

A herdabilidade para o caráter crescimento micelial $\left(h^{2}\right)$ foi 


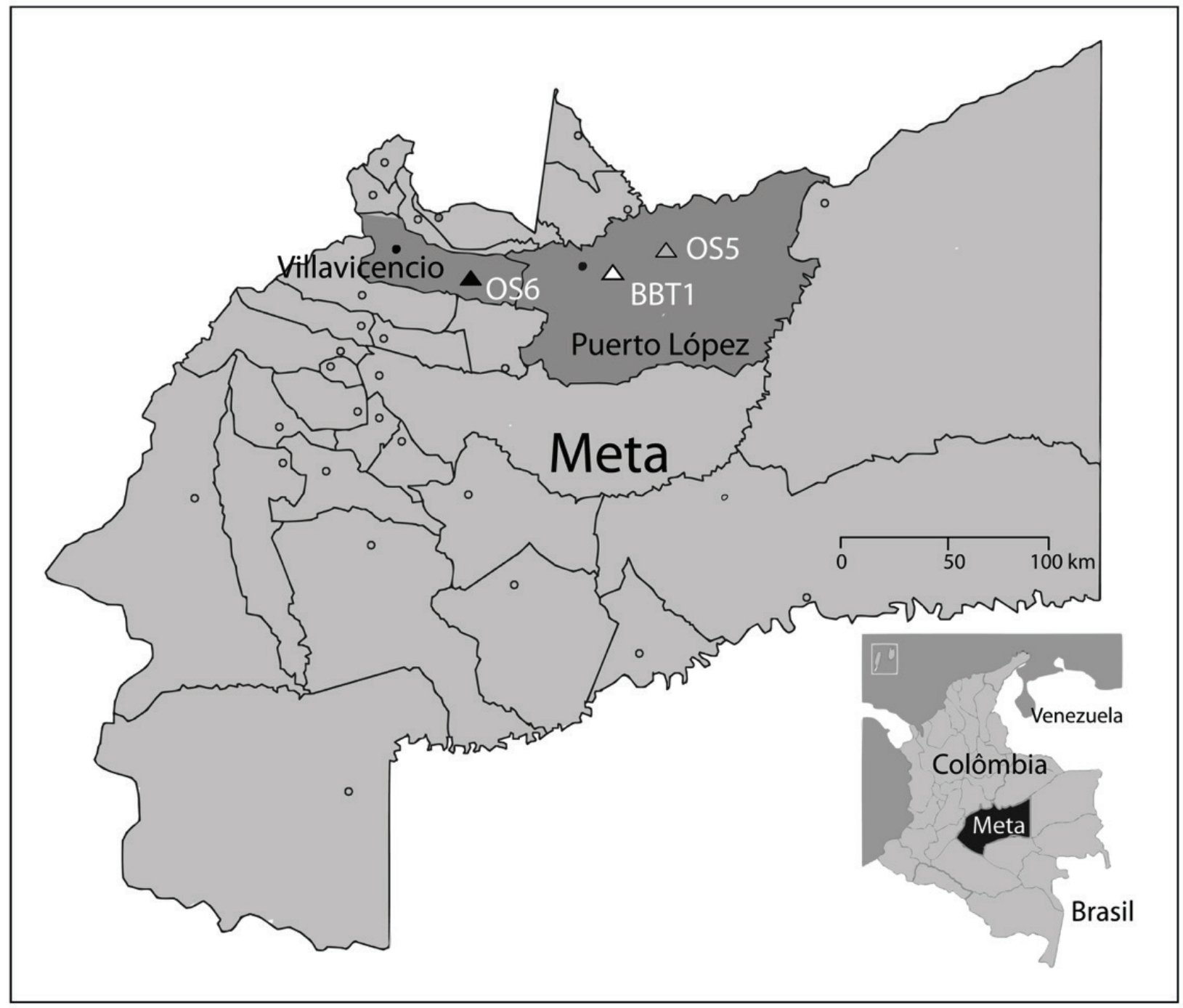

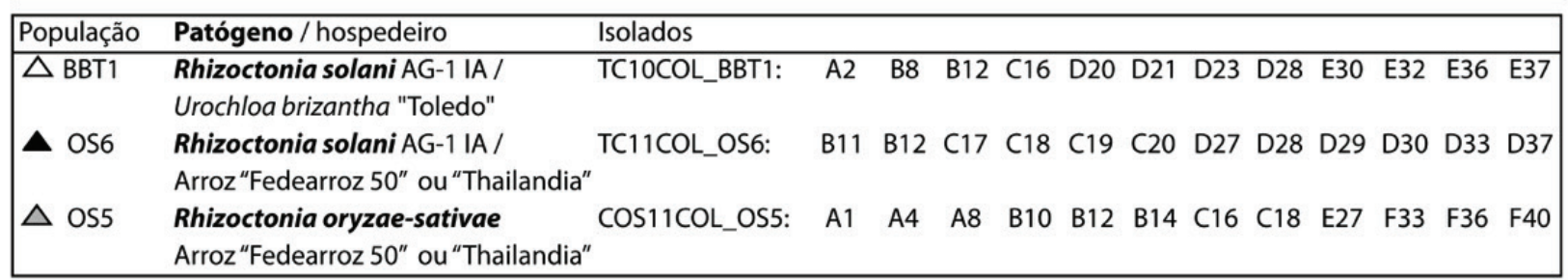

Figura 1. Localização geográfica das áreas onde amostrou-se populações de Rhizoctonia solani AG-1 IA de Urochloa brizantha (BBT1) e do arroz (OS6) e de R. oryzae-sativae do arroz (OS5) nos Llanos orientais Colombianos a a Pontos redondos vazios indicam cedes dos municípios.

calculada como a razão entre a variância genética $\left(I_{G}\right)$ e a variância fenotípica $\left(I_{P}\right)$, ambas padronizadas $\left(I_{P}=\mathrm{I}_{G}+I_{E}\right)$. Os intervalos de confiança a $95 \%$ para as estimativas de $h^{2}$ foram calculados por meio de análise de bootstrap ordinário ou não-paramétrico (11) baseada em 999 re-amostragens de dados originais, onde em cada re-amostragem obteve-se os componentes de variâncias padronizadas e as respectivas herdabilidades. O bootstrap foi implementado no ambiente $\mathrm{R}$ onde utilizaram os pacotes da distribuição base e o pacote "lme4" disponível no http://CRAN.R-project.org/package=lme4 $(4,11)$, conforme o modelo misto considerado.

Tanto as estimativas de $h^{2}$ quanto de $I_{G}$ predizem a resposta à seleção $R\left(R=h^{2} i r_{P}\right.$, onde $i=$ intensidade de seleção e $r_{P}=$ desvio padrão fenotípico do atributo antes da seleção, de acordo com Falconer \& Mackay (12); ou $R=I_{G} X$, onde $X=$ intensidade de seleção, de acordo com Houle (15)). Dessa forma, ambos podem ser consideradas medidas de evolucionabilidade ou do potencial adaptativo de uma população $(14,20,21,29)$.

\section{RESULTADOS E DISCUSSÃO}

Quanto ao crescimento micelial, sob diferentes temperaturas, os efeitos dos fatores população e isolados dentro de populações foram significativos indicando diferenças entre as populações e entre isolados de Rhizoctonia spp. dentro de populações (Tabela 1). 
Observaram-se diferenças significativas entre a população OS5 de $R$. oryzae-sativae e as populações BBT1 e OS6 de $R$. solani AG-1 IA. $\mathrm{O}$ aumento da temperatura de 25 para $35^{\circ} \mathrm{C}$ promoveu, de forma similar, redução na taxa de crescimento micelial de $R$. solani AG-1 IA nas populações BBT1 e OS6 (Figura 2). O oposto ocorreu com a população OS5, cujos isolados de $R$. oryzae-sativae apresentaram aumento significativo de crescimento com o aumento da temperatura. Dessa maneira, nossos resultados confirmaram o relato que $R$. oryzaesativae do arroz é mais adaptada (em termos de crescimento micelial) à temperaturas mais elevadas (3).

Observou-se também, que os isolados de $R$. solani AG-1 IA das populações BBT1 e OS6 da Colômbia apresentaram comportamento semelhante aos descritos por Costa-Souza et al. (10), que relatam que a temperatura ótima para o crescimento micelial do patógeno da queima da bainha do arroz do Brasil era de $25^{\circ} \mathrm{C}$. No geral, a temperatura de $35^{\circ} \mathrm{C}$ representou condição de estresse para as populações de $R$. solani AG-1 IA de Urochloa e de arroz amostradas na Colômbia.

A respeito do efeito de estresse térmico sobre as medidas de evolucionabilidade das populações dos patógenos, de fato observou-se que o aumento da temperatura promoveu mudanças significativas na variância genotípica $I_{G}$ das populações.

Enquanto para as populações BBT1 e OS6 de $R$. solani AG-1 IA a $I_{G}$ diminuiu significativamente, para a população OS5 de $R$. oryzae-sativae detectou-se aumento significativo da $I_{G}$ a $35^{\circ} \mathrm{C}$ (Figura 3). Sob condição de estresse térmico a $35^{\circ} \mathrm{C}$, a $h^{2}$ diminuiu significativamente nas populações BBT1 (de 0,84 a $25^{\circ} \mathrm{C}$ para 0,70 a $35^{\circ} \mathrm{C}$ ) e OS6 (de 0,92 para 0,56 ) de $R$. solani AG-1 IA, mantendose estável na população OS5 de $R$. oryzae-sativae do arroz (de 0,61 a 0,56).

Quando R. solani AG-3 PT da batata, cujo ótimo de temperatura é $24^{\circ} \mathrm{C}$, foi submetido a condições de estresse de temperatura $\left(27^{\circ} \mathrm{C}\right)$ observou-se, também, diminuição de $h^{2}$ para crescimento micelial (28). É plausível que as duas populações de $R$. solani AG-1 IA

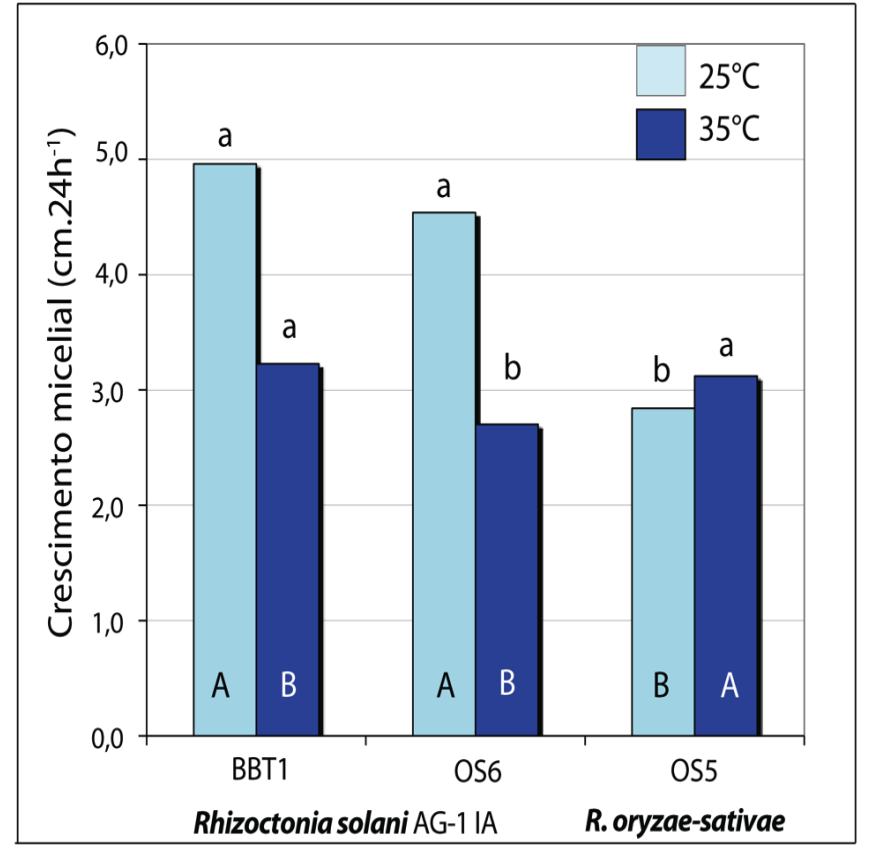

Figura 2. Resposta fenotípica para crescimento micelial sob condições ótimas e de estresse de temperatura em populações de Rhizoctonia solani AG- 1 IA de Urochloa e do arroz e de R. oryzae-sativae do arroz ${ }^{\text {. }}$. ${ }^{a}$ Barras de mesma cor seguidas de mesma letra minúscula não são significativamente diferentes pelo teste $t$ a $\mathrm{p} \leq 0.05$. Barras de cores diferentes seguidas de mesma letra maiúscula também não são significativamente diferentes pelo mesmo teste.

Tabela 1. Modelo linear geral testando os efeitos de população, isolados e ambiente (temperatura) e suas interações sobre o crescimento micelial in vitro dos fitopatógenos Rhizoctonia solani AG-1 IA de Urochloa brizantha (BBT1) e do arroz (OS5) e R. oryzae-sativae do arroz (OS6) nos Llanos orientais Colombianos a .

\begin{tabular}{|c|c|c|c|c|}
\hline Fontes de variação & GL & SQ & QM & $F$ calculado $^{a}$ \\
\hline Isolado (População) & 33 & 4,0900 & 0,1239 & $5,95 * * *$ \\
\hline Ambiente & 1 & 7,6019 & 7,6019 & $364,35 * * *$ \\
\hline Ambiente x Isolado (População) & 33 & 0,8994 & 0,0272 & $1,31^{\mathrm{ns}}$ \\
\hline \multirow{2}{*}{ Fontes de variação } & GL & \multicolumn{3}{|c|}{$F$ calculado (dentro de populações) } \\
\hline & & BBT1 & OS6 & OS5 \\
\hline Isolado & 11 & $7,34 * * *$ & $3,57 * * *$ & $9,90^{* * *}$ \\
\hline Ambiente & 1 & $216,11 * * *$ & $366,90 * * *$ & $69,00 * * *$ \\
\hline Coeficiente de variação \% (CV) & & 9,65 & 11,36 & 6,99 \\
\hline
\end{tabular}

${ }^{a}$ Significativo pelo teste $F$ a $p \leq 0.001(* * *)$ e não significativo $\left({ }^{\text {ns }}\right)$. Nenhuma interação entre o fator réplica do experimento e os fatores população, isolado(população) e ambiente fo detectada. Dessa forma, as duas réplicas do experimento foram combinadas. 

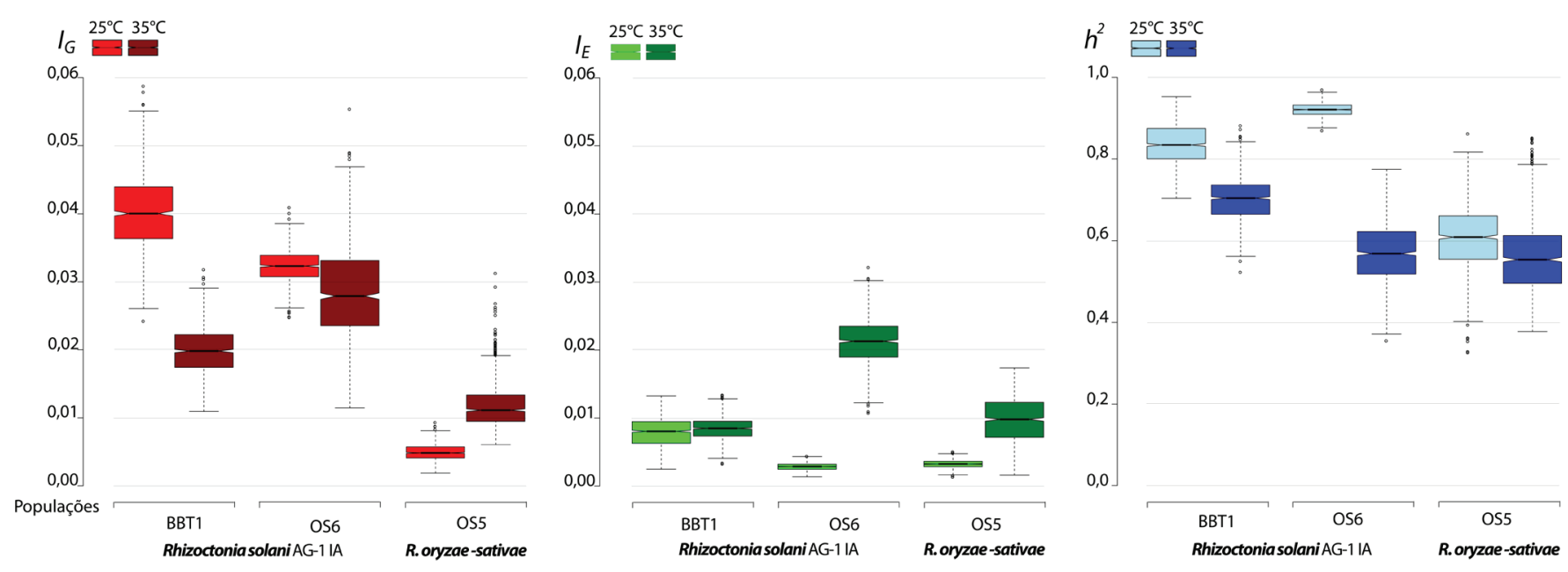

Figura 3 - Efeito da temperatura sobre os componentes de evolucionabilidade para o crescimento micelial in vitro de populações Rhizoctonia solani AG-1 IA de Urochloa brizantha (BBT1) e do arroz (OS6) e $R$. oryzae-sativae do arroz (OS5) dos Llanos orientais Colombianos a 25 e a $35^{\circ} \mathrm{C}$ a ${ }^{a}$ A temperatura de $35^{\circ} \mathrm{C}$ é considerada condição de estresse térmico para $R$. solani AG-1 IA (10). Os componentes de evolucionabilidade $I_{G} I_{E}$ e $h^{2}$ correspondem a medidas de variância genética $\left(V_{G}\right)$, ambiental $\left(V_{E}\right)$ e de herdabilidade $\left(h^{2}\right)$ padronizadas pelo quadrado da média do crescimento no respectivo ambiente (15). Os diagramas de caixas (boxplots) contém a linha da mediana aproximadamente em seu centro e $50 \%$ dos dados (entre os quartís 25 e 75\%) gerados por bootstrap considerando 999 re-amostragem. As barras verticais indicam os valores máximos e mínimos observados e os círculos os valores atípicos. O entalhe marca o intervalo de confiança de $95 \%$ para as medianas.

que apresentaram diminuição da $h^{2}$ para crescimento micelial sob estresse térmico (em relação à população $R$. oryzae-sativae, adaptada a altas temperaturas) tenham experimentado acúmulo diferencial de mutações deletérias ao longo de sua história evolutiva, com efeito epistático negativo agravado sob estresse (18). Outras hipóteses prevêem que a diminuição da $h^{2}$ ocorre porque o estresse aumenta a variação ambiental sem afetar necessariamente a variação genética aditiva, ou porque o estresse impede que os organismos alcancem seu potencial genético sob uma condições limitantes de nutrição com, consequente redução da variância genética $(28,29)$.

Entretanto, os valores de herdabilidade $\left(h^{2}=0,63 \pm 0,07\right.$, a $\left.35^{\circ} \mathrm{C}\right)$ para crescimento micelial sob condições de estresse de temperatura detectados para $R$. solani AG-1 IA foram ainda relativamente altos (18) indicando que a contribuição relativa das diferenças genéticas foi maior que a plasticidade fenotípica do patógeno em diferentes condições ambientais (Figura 3). Essa alta herdabilidade para crescimento micelial a $35^{\circ} \mathrm{C}$ (semelhante, inclusive à espécie $R$. oryzae-sativae adaptada a altas temperaturas) indica que as populações de $R$. solani AG-1 IA estudadas tem capacidade de adaptação ao estresse térmico.

\section{AGRADECIMENTOS}

Os autores agradecem às agências de fomento pela concessão das seguintes modalidades de bolsas e auxílios: CNPq - Pq2 (307361/20128) e CNPq/MCT - Universal 14/2010 (481756/2010-8) a P.C. Ceresini, FAPESP - AP (2010/15704-5) a P.C. Ceresini, e FAPESP - MSc (2013/11944-0) a D.A.S. Pereira. L.M. Ramos-Molina foi discente de doutorado do Programa de Pós-Graduação em Genética e Melhoramento de Plantas, da UNESP Campus de Jaboticabal e bolsista CNPq - DR (140564/2009-8), enquanto. D.A.S. Pereira e S.N.C. Vicentini foram discentes de mestrado do Programa de Pós-Graduação em Agronomia
"Sistema de Produção", da UNESP Campus de Ilha Solteira e bolsistas CAPES (Coordenação de Formação de Pessoal de Nível Superior).

\section{REFERÊNCIAS}

1. Abrashev, R.; Stoitsova, S.; Krumova, E.; Pashova, S.; Paunova-Krasteva, T.; Vassilev, S.; Dolashka-Angelova, P.; Angelova, M. Temperature-stress tolerance of the fungal strain Aspergillus niger 26: physiological and ultrastructural changes. World Journal of Microbiology and Biotechnology, Hull, v.30, n.5, p.1661-1668, 2014.

2. Alvarez, E.; Latorre, M.; Bonilla, X.; Sotelo, G.; Miles, J.W. Diversity of Rhizoctonia spp. causing foliar blight on Brachiaria in Colombia and evaluation of Brachiaria genotypes for foliar blight resistance. Plant Disease, Chichester, v.97, n.6, p.772-779, 2013.

3. Amirmijani, A.R.; Khodaparast, S.A.; Padasht, F.; Rabiei, B. Biology of Rhizoctonia oryzae-sativae causal agent of rice aggregate sheath spot disease in Guilan Province. Iranian Journal of Plant Pathology, Tehran, v.49, n.1, p.15-16, 2013.

4. Bates, D.; Maechler, M. Ime4: Linear mixed-effects models using S4 classes. R package version 0.999375-34. Linz: Foundation for Open Access Statistics, 2010

5. Bernardes de Assis, J.; Peyer, P.; Rush, M.C.; Zala, M.; McDonald, B.A.; Ceresini, P. C. Divergence between sympatric rice- and soybean-infecting populations of Rhizoctonia solani anastomosis group-1 IA. Phytopathology, St. Paul, v.98, n.12, p.1326-1333, 2008.

6. Cardona, R.; Rodríguez, H.; Nass, H. Mancha bandeada en maíz causada por Rhizoctonia solani en el estado Portuguesa, Venezuela. Fitopatologia Venezolana, Maracay, v.12, n.2, p.32-33, 1999.

7. Ceresini, P.C. Rhizoctonia como fitopatógeno: biologia e diversidade de Rhizoctonia solani em agroecossistemas tropicais e perspectivas de manejo da rizoctoniose usando resistência de plantas. In: Freitas, A.S.; Dornelas, G.A.; Silva, J.C.P.; Salum, L.A.; Pimenta, L.; Pedroso, L.A.; Faria, M.D.R.; Paula, P.V.A.A.; Martins, S.A. (Ed.). Sanidade de raízes. São Carlos: Suprema Gráfica e Editora, 2014. p.177-190.

8. Chavarro Mesa, E.; Ceresini, P.C.; Ramos Molina, L.M.; Pereira, D.A.S.; Schurt, D.A.; Vieira, J.R.; Poloni, N.M.; Mcdonald, B.A. The Urochloa 
foliar blight and collar rot pathogen Rhizoctonia solani AG-1 IA emerged in South America via a host shift from rice. Phytopathology, St. Paul, v.105, n.11, p.1475-1486, 2015.

9. Ciat. Annual Report: Tropical Forages Program. Cali: Centro Internacional de Agricultura Tropical, 1993. (Documento, 166).

10. Costa-Souza, E.; Kuramae, E.E.; Nakatani, A.K.; Basseto, M.A.; Prabhu, A.S.; Ceresini, P.C. Caracterização citomorfológica, cultural, molecular e patogênica de Rhizoctonia solani Kühn associado ao arroz em Tocantins, Brasil. Summa Phytopathologica, Botucatu, v.33 n.2, p.129-136, 2007.

11. Davison, A.C.; Hinkley, D.V. Bootstrap methods and their application. New York: Cambridge University Press, 1997. 592p.

12. Falconer, D.S.; Mackay, T.F.C. Introduction to quantitative genetics. 4 th ed. Harlow: Longmans Green, 1996. 464p.

13. González, D.; Carling, D.E.; Kuninaga, S.; Vilgalys, R.; Cubeta, M.A. Ribosomal DNA systematics of Ceratobasidium and Thanatephorus with Rhizoctonia anamorphs. Mycologia, New York, v.93, p.1138-1150, 2001.

14. González-Vera, A.D.; Bernardes-De-Assis, J.; Zala, M.; Mcdonald, B.A.; Correa-Victoria, F.; Graterol-Matute, E.J.; Ceresini, P.C. Divergence between sympatric rice- and maize-infecting populations of Rhizoctonia solani AG 1 IA from Latin America. Phytopathology, St. Paul, v.100, n.2, p.172-182, 2010.

15. Houle, D. Comparing evolvability and variability of quantitative traits. Genetics, Rockville, v.130, p.195-204, 1992.

16. Johanson, A.; Turner, H.C.; Mckay, G.J.; Brown, A.E. A PCR-based method to distinguish fungi of the rice sheath-blight complex, Rhizoctonia solani, $R$. oryzae and $R$. oryzae-sativae. FEMS Microbiology Letters, Oxford, v.162, n.289-294, 1998.

17. Jones, R.K.; Belmar, S.B. Characterization and pathogenicity of Rhizoctonia spp. isolated from rice, soybean, and other crops grown in rotation with rice in Texas. Plant Disease, Chichester, v.73, p.1004-1010, 1989.

18. Kishony, R.; Leibler, S. Environmental stresses can alleviate the average deleterious effect of mutations. Journal of Biology, London, v.2, n.14, 2003.

19. Lehtonen, M.J.; Ahvenniemi, P.; Wilson, P.S.; German-Kinnari, M.; Valkonen, J. P. T. Biological diversity of Rhizoctonia solani (AG-3) in a northern potato-cultivation environment in Finland. Plant Pathology, Loughborough, v. 57, p.141-151, 2008.
20. Matsumoto, M. Trials of direct detection and identification of Rhizoctonia solani $\mathrm{AG} 1$ and $\mathrm{AG} 2$ subgroups using specifically primed PCR analysis. Mycoscience, Nonoichi, v.43, p.185-189, 2002.

21. Menzies, J.D. The first century of Rhizoctonia solani. In: Parmeter, J.R. (Ed.). Rhizoctonia solani: Biology and Pathology. Berkeley. University of California Press, 1970. p.62-92.

22. Pereira, D.A.D.S.; Ceresini, P.C.; Castroagudín, V.L.; Ramos-Molina, L.M.; Chavarro-Mesa, E.; Negrisoli, M.M.; Campos, S.N.; Pegolo, M.E.S.; Takada, H.M. Population genetic structure of Rhizoctonia oryzae-sativae from rice in Latin America and its adaptive potential to emerge as a pathogen on Urochloa Pastures. Phytopathology, St. Paul, v.107, n.1, p.121-131, 2016.

23. Poloni, N.M.; Ramos-Molina, L.M.; Chavarro-Mesa, E.; Garcia, I.L.; Ceresini, P.C. Evidência de que o fungo Rhizoctonia solani AG-1 IA adaptado à Urochloa na Colômbia mantém ampla gama de hospedeiros incluindo o milho. Summa Phytopathologica, Botucatu, v.42, p.228-232, 2016.

24. R Development Core Team. R: A language and environment for statistical computing.Vienna: R Foundation for Statistical Computing, 2008.

25. Ramos-Molina, L.M.; Chavarro-Mesa, E.; Pereira, D.A.D.S.; Silva-Herrera, M.D.R.; Ceresini, P.C. Rhizoctonia solani AG-1 IA infecta arroz e braquiária nos Llanos Colombianos. Pesquisa Agropecuária Tropical, Goiânia, v.46, n.1, p.67-71, 2016 .

26. Sas Institute. SAS OnlineDoc. Version 9.1.3. Cary: SAS Institute, 2008.

27. Vicentini, S.N.C.; Santos, D.A.P.D.; Castroagudín, V. L.; Dorigan, A.F.; Ceresini, P.C. Adaptabilidade e danos potenciais de Rhizoctonia oryzae-sativae ao milho. Summa Phytopathologica, Botucatu, v.43, n.3, p.1-7, 2017.

28. Willi, Y.; Frank, A.; Heinzelmann, R.; Kälin, A.; Spalinger, L.; Ceresini, P.C. The adaptive potential of a plant pathogenic fungus, Rhizoctonia solani AG-3, under heat and fungicide stress. Genetica, Netherland, v.139, n.7, p.903-908, 2011.

29. Willi, Y.; Van Buskirk, J.; Hoffmann, A.A. Limits to the adaptive potential of small populations. Annual Review of Ecology, Evolution, and Systematics, Palo Alto, v.37, n.1, p.433-458, 2006.

30. Zhan, J.; Mcdonald, B.A. Thermal adaptation in the fungal pathogen Mycosphaerella graminicola. Molecular Ecology, Oxford, v.20, p.16891701, 2011. 